\title{
Transformation of residual biomass into adsorbent materials: Applications to treatment of liquid effluents
}

\author{
Samia Glissi ${ }^{1, *}$, Meriem Tarbaou ${ }^{1}$, Laila Makouki ${ }^{1}$, Said Mansouri ${ }^{1}$, Khadija Legrouri ${ }^{3}$, Hassan \\ Hannache $^{2}$, Noureddine Fenineche ${ }^{4}$ and Mina Oumam ${ }^{1}$ \\ 1. Thermo-Structural Materials, Polymers and Radiochemistry Team, LIMAT, Faculty of Sciences Ben M'Sik, \\ University Hassan II, Casablanca, Morocco \\ 2. Materials Science and Nano-Engineering Department, University Mohammed VI Polytechnic, Ben Guerir, \\ Morocco \\ 3. Higher Institute of Nursing Professions and Health Techniques, ISPITS, Agadir, Morocco \\ 4. ICB-PMDM-LERMPS-University of Technology Belfort-Montbéliard, UTBM, Belfort, France
}

\begin{abstract}
In this work, some adsorbent materials were prepared from residual biomass, which constitutes a real hazard for the environment and human health. So, in order to valorize this vegetal resource, a process of transformation was studied. The residual biomass was turned into adsorbent materials under the effect of chemical activation with phosphoric acid which allows the development of a large pore in the activated materials. The optimization of the conditions for the elaboration of our adsorbents was realized by experimental design by evaluating some parameters (percentage of phosphoric acid, temperature and time of activation) and their effects on the responses (capacity of adsorption of methylene blue, adsorbent yield), these parameters were selected after a screening study. The activation of our residual biomass was effected with $60 \%$ of phosphoric acid in $225^{\circ} \mathrm{C}$ while $115 \mathrm{~min}$. The studied biomass was characterized by different physic-chemical methods (Differential Thermal Analysis /Thermogravimetric Analysis (DTA/TGA), Scanning Electron Microscopy (SEM), Raman and X-Ray Diffraction (XRD)); the results of characterization show the presence of the excellent textural and structural properties. The application of the best adsorbent in the removal of textile dyes (methylene blue) from aqueous solutions was studied. The impact of various parameters such as contact time, $\mathrm{pH}$ and concentration on the removal was evaluated by batch method. The adsorption isotherms were studied using Langmuir and Freundlich isotherm models. Langmuir isotherm provided the best fit to the equilibrium data with a correlation coefficient equal to 0.998. This result shows the presence of monolayer adsorption. The experiments demonstrated that the removal of methylene blue followed the pseudo-second-order kinetic model. The correlation coefficient is consistent and equal to unity, and the experimental $\mathrm{q}_{\mathrm{e}}$ value (44.17) was agreed with the calculated $\mathrm{q}_{\mathrm{e}}$ value (45.45) of pseudosecond-order then the value of pseudo-first-order which confirm a chemisorption process. The obtained results revealed that the elaborated material is an effective adsorbent for the removal of methylene blue.
\end{abstract}

Keywords: Biomass; Adsorbent materials; Characterization; Liquid effluents; Adsorption isotherms.

\section{Introduction}

Biomass is a term used to describe all organic matter produced by photosynthesis, existing on the earth's surface. They include all water- and land-based vegetation and trees, and all waste biomass such as municipal solid waste (MSW), municipal biosolids (sewage), and animal wastes (manures), forestry and agricultural residues, and certain types of industrial wastes ${ }^{1,2}$.

Vegetal biomass valorisation projects could bring out new industrial sectors, creating sustainable activities and jobs, while helping to control the consumption of non-renewable resources and the fight against climate change. However, the industrial exploitation of

*Corresponding author: Samia Glissi

Email address: glissi.sam@gmail.com

DOI: http://dx.doi.org/10.13171/mjc91190810530sg vegetal biomass generates large quantities of solid residues which certainly represent an undeniable economic value, but whose accumulation in a given place constitutes a real hazard for the environment and human health. Such as water pollution that represents water contaminated by thousands of organic, inorganic and biological pollutants ${ }^{3-6}$. Most organic pollutants belonged to different classes such as pesticides, phenols, plasticizers, biphenyls, detergents, oils, hydrocarbons, pharmaceuticals, and so on ${ }^{7-11}$. The effects and toxicities of these contaminants are discussed in various literature and research articles ${ }^{8,12,13}$. 
So in order to avoid these effects, the exploration of new ways of exploiting the residual biomass is, therefore, a necessity ${ }^{14}$.

This study is intended to highlight the possibility to use residual biomass as new material to remove and adsorb hazardous pollutants from industrial effluents. Nowadays, it is known that pollution due to synthetic dyes is considered a serious public concern. An untreated dyes cause chemical and biological changes and lead several environmental and health hazards. Nearly, 10.000 dyes available commercially and different group of dyes can be discerned ${ }^{15,16}$. Consequently, approximately $1000000 \mathrm{~kg} /$ year of dyes are discharged into waste streams by the textile industry ${ }^{17}$. Most of the industrial activities use synthetic dyestuffs in a high number of operations, they consume large quantities of water and they generate a considerable amount of colored wastewater. They can be highly toxic and carcinogenic to human health. Methylene bleu (MB) 3.7-bis(dimethylamino)-phenazathionium chloride (a thiazine cationic dye) is used for coloring paper, temporary hair colorant, dyeing cotton, wools and so on ${ }^{18}$.

Several physicochemical wastewater treatment techniques were developed for dyes recovery from industrial effluents including physical and chemical processes such as precipitation, sedimentation, ultrafiltration, flotation, color irradiation, ozonation and coagulation. For the above-mentioned technologies are sometimes inappropriate, especially for low-concentration solutions due to economic, technical or environmental reasons. Adsorption is an effective alternative process for treatment of contaminated wastewater in terms of simplicity of design and operation, and insensitivity of toxic substances ${ }^{19-29}$. A considerable amount of researches have been done on the development of effective, low cost and readily available alternative biosorbents ${ }^{30-41}$. The main objective of this research is to study the ability of the residual biomass (Residual of Marjoram $(\mathrm{M})$, Oregano $(\mathrm{O})$ and Rosmarinus $(\mathrm{R})$ ) for removing methylene blue (MB) from aqueous solutions. A laboratory study was conducted to investigate the feasibility of the use of residual biomass as adsorbent on batch experiments. The effect of $\mathrm{pH}$ value, time, and various initial concentrations on adsorption capacity of residual biomass were evaluated. Adsorption kinetics and isotherms equilibrium were examined ${ }^{42-50}$.

\section{Materials and methods}

\subsection{Preparation of the biomass}

The biomass used in this study was collected from biomolecules laboratory after extraction of all organic molecules with biological interest. The residual biomass was identified and dried at $110^{\circ} \mathrm{C}$ for $24 \mathrm{~h}^{47,50}$. It was ground and reduced to a particle size between 1 and $2 \mathrm{~mm}$; the obtained materials were have undergone a chemical activation process using phosphoric acid with $60 \%$. This value is removed from the results of the experimental design methodology used in order to reduce the number of experimental trials necessary for evaluation of the parameters studied (percentage of phosphoric acid, activation temperature and activation time) and their effects on the responses (adsorption capacity of methylene blue and adsorbent yield). The studied parameters were selected after a screening study. The optimised adsorbent materials obtained were elaborate with $60 \%$ of phosphoric acid in $225^{\circ} \mathrm{C}$ and at $115 \mathrm{~min}$. The obtained adsorbent materials were washed with distilled water until all the excess acid was eliminated, dried, ground and sifted to obtain a powder with a particle size capable of passing through a $100 \mu \mathrm{m}$ sieve; they were finally kept in a hermetic bottle for subsequent uses ${ }^{45-50}$.

\subsection{Chemicals}

All chemicals used in this study were of analytical grade and solutions were prepared using deionized and distilled water. The stock solution of methylene blue was prepared by dissolving $\mathrm{C}_{16} \mathrm{H}_{18} \mathrm{ClN}_{3} \mathrm{SxH}_{2} \mathrm{O}_{\mathrm{X}}$ of Sigma-Aldrich in water (Figure 1). The concentration of leftover methylene blue dyes in the aqueous solution was measured colorimetrically using a UV/visible spectrophotometer (UV2300). The absorbance of the color of methylene blue was read at $664 \mathrm{~nm}$<smiles></smiles>

Figure 1. Chemical Structure of Methylene bleu (MB)

\subsection{Physicochemical characterization of biomass}

The characterization of adsorbent materials was carried out by physico-chemical methods: thermal analysis (DTA/TGA) was realized by Discovery TGA, DTA instrument between room temperature and a final temperature of $1000^{\circ} \mathrm{C}$, with a temperature rise rate of $10^{\circ} \mathrm{C} / \mathrm{min}$. This two analysis provide valuable information about physico-chemical properties of studied materials. It allows us to understand the phenomena that can influence the transformation of the material during a heat treatment 48,49. Scanning electron microscopy (SEM) analysis was performed by Hirox SH-3500MB to have an idea about the external morphology and porosity of raw and elaborate materials ${ }^{48-50}$. XRD analysis was realized by Bruker D2 Phaser in order to mention the nature of the crystalline phases $48,49,51$.

The Raman spectroscopic analysis was performed by a DXR Raman spectrometer with an excitation wavelength of $633 \mathrm{~nm}$ with a power of $6 \mathrm{~mW}$. This analysis allows to observe and characterize the 
molecular composition and external structure of a studied materials $35,39,50$.

\subsection{Batch mode adsorption studies}

Removal of methylene blue (MB) onto the best adsorbent (M). The choice of this material as the best adsorbent is based on his structure and porosity are shown in results of characterisation, was carried out by batch method and the influence of various parameters such as the effect of $\mathrm{pH}$, contact time, and concentration, were studied. For each experimental run, $100 \mathrm{~mL}$ of $\mathrm{MB}$ solution of known concentration was taken in a $250 \mathrm{~mL}$ stoppered reagent bottle, $\mathrm{pH}$ was adjusted to the desired value by the addition of dilute aqueous solutions of $\mathrm{HCl}$ and $\mathrm{NaOH}$, and $0.1 \mathrm{~g}$ of adsorbent was added. This mixture was agitated at room temperature (298K) using a mechanical shake at a constant rate of $250 \mathrm{rpm}$ for $60 \mathrm{~min}$ to attain equilibrium. At the end of the predetermined time intervals, the sample was taken out, and the supernatant solution was separated from the adsorbent through polytetrafluoroethylene syringe filters (pore size $0.45 \mu \mathrm{m}$ ) and analyzed the concentration of $\mathrm{MB}$ remaining in a solution using UV/visible spectrophotometer. Effect of $\mathrm{pH}$ was studied over the range of 3.0-11.0. Kinetics and effect of contact time on adsorption were determined at different time intervals over a range of 0-700 min. Adsorption isotherms were studied by varying the initial $\mathrm{MB}$ concentration from 20 to $120 \mathrm{mg} / \mathrm{L}$. The amount of adsorbed MB per gram of adsorbent at equilibrium, $\mathrm{q}_{\mathrm{e}}$ $(\mathrm{mg} / \mathrm{g})$, and the removal percentage (\% removal), were calculated using the following equations:

$q_{e}=\frac{\left(C_{0}-C_{e}\right) \cdot V}{m}$

\%removal $=\frac{\left(C_{0}-C_{e}\right)}{C_{0}} \times 100$

Where $\mathrm{C}_{0}$ and $\mathrm{C}_{\mathrm{e}}$ are the initial and equilibrium concentrations of $\mathrm{MB}(\mathrm{mg} / \mathrm{L}) . \mathrm{V}$ is the volume of $\mathrm{MB}$ solution (L), and $\mathrm{m}$ is the weight of used adsorbent (g).

\subsection{Adsorption isotherm models}

The adsorption equilibrium data of MB onto the adsorbent were analyzed in terms of Langmuir and Freundlich isotherm models ${ }^{51}$. The relative coefficients of these models were calculated using least-squares fitting. Langmuir model is based on the assumption that adsorption energy is constant and independent of surface coverage. The maximum adsorption occurs when the surface is covered by a monolayer of the adsorbate. The Langmuir isotherm is given by equation 3 :

$q_{e}=\frac{Q_{m} b C_{e}}{1+b C_{e}}$

The linear form of the Langmuir isotherm equation is given as:

$$
\frac{C_{e}}{q_{e}}=\frac{1}{Q_{m} b}+\frac{C_{e}}{Q_{m}}
$$

Where $\mathrm{C}_{\mathrm{e}}$ is the equilibrium concentration of the adsorbate $(\mathrm{mg} / \mathrm{L}), \mathrm{q}_{\mathrm{e}}$ is the amount of adsorbate adsorbed per unit mass of adsorbent ( $\mathrm{mg} / \mathrm{g}$ ), $\mathrm{b}$ is the Langmuir adsorption constant $(\mathrm{L} / \mathrm{mg})$, and $\mathrm{Q}_{\mathrm{m}}$ is the theoretical maximum adsorption capacity $(\mathrm{mg} / \mathrm{g})$.

The essential characteristics of the Langmuir isotherm can also be expressed in terms of a dimensionless constant of separation factor or equilibrium parameter, $\mathrm{R}_{\mathrm{L}}$, which is defined as

$$
R_{L}=\frac{1}{\left(1+b C_{0}\right)}
$$

Where $\mathrm{b}$ is the Langmuir constant and $\mathrm{C}_{0}$ is the initial concentration of metal ions. The $\mathrm{R}_{\mathrm{L}}$ value indicates the shape of isotherm ${ }^{52} \cdot \mathrm{R}_{\mathrm{L}}$ values between 0 and 1 indicate favorable adsorption, while $\mathrm{R}_{\mathrm{L}}>1, \mathrm{R}_{\mathrm{L}}=1$, and $\mathrm{R}_{\mathrm{L}}=0$ indicate unfavorable, linear, and irreversible adsorption isotherms.

Freundlich isotherm describes the different surface energies by multilayer adsorption and is expressed in linear form as:

$$
\ln q_{e}=\ln K_{F}+\left(\frac{1}{n}\right) \ln C_{e}
$$

The constants $\mathrm{K}_{\mathrm{F}}$ and $\mathrm{n}$ of the Freundlich model are those indicative of the relative adsorption capacity of the adsorbent and the intensity of the adsorption, respectively. For values in the range $1<\mathrm{n}<10$, adsorption is favorable ${ }^{53}$.

\subsection{Adsorption kinetics models}

In order to analyze the adsorption kinetics of MB onto the adsorbent, two kinetic models; pseudo-first-order and pseudo-second-order kinetic were applied for the experimental data. The pseudo-first-order equation can be expressed as ${ }^{51}$ :

$\ln \left(q_{e}-q_{t}\right)=\ln q_{e}-\frac{K_{1}}{2.303} t$

Where $\mathrm{q}_{\mathrm{e}}$ and $\mathrm{q}_{\mathrm{t}}$ are the amounts adsorbed at equilibrium and at time $\mathrm{t}(\mathrm{mg} / \mathrm{g})$, and $\mathrm{k}_{1}$ is the rate constant of the pseudo-first-order adsorption $\left(\mathrm{min}^{-1}\right)$. The adsorption rate constant $\mathrm{k}_{1}$, can be calculated by plotting $\ln \left(\mathrm{q}_{\mathrm{e}}-\mathrm{q}_{\mathrm{t}}\right)$ versus $\mathrm{t}$.

The pseudo-second-order kinetic model can be represented in the following form:

$$
\frac{t}{q_{t}}=\frac{1}{K_{2} q_{e}^{2}}+\frac{1}{q_{e}} t
$$

Where $\mathrm{k}_{2}(\mathrm{~g} / \mathrm{mg} \mathrm{min})$ is the rate constant of secondorder adsorption. $\mathrm{k}_{2}$ and $\mathrm{q}_{\mathrm{e}}$ can be obtained from the intercept and slope of plotting $\mathrm{t} / \mathrm{q}_{\mathrm{t}}$ versus $\mathrm{t}$. 


\section{Results and Discussion}

\subsection{Physico-chemical Characterization}

\subsubsection{Thermal analysis (DTA/TGA)}

Differential Thermal Analysis and Thermogravimetric Analysis (DTA/TGA) were performed on the studied to understand the phenomena that can influence the transformation of the material during a heat treatment and determine the temperature range where the mass loss of the biomass is carried out. The results are shown in Figure 2.

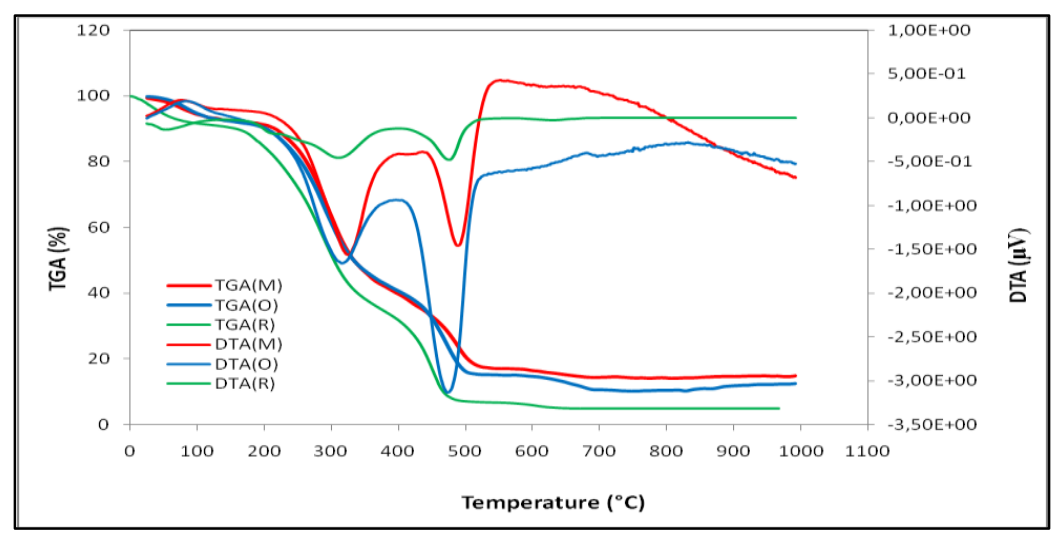

Figure 2. DTA/TGA Thermograms of the studied biomass samples

The TGA curves shown in Figure 2 represent the evolution of the normalized mass of the studied biomass samples during pyrolysis as a function of temperature. From these curves, two distinct losses are observed. A slight loss due mainly to the departure of the water which takes place between 25 and $225^{\circ} \mathrm{C}$ and a second loss was going from 225 to $525^{\circ} \mathrm{C}$ which corresponds to the departure of the molecules resulting from the decomposition of the organic matter.

The DTA curves of the biomass samples show the evolution of the specific heat as a function of temperature. These curves reveal the presence of endothermic peaks located between 300 and $500^{\circ} \mathrm{C}$, which are attributable to the dehydration and the pyrolysis reaction.

The obtained results show that the studied biomass acts in the same way versus the temperature and that

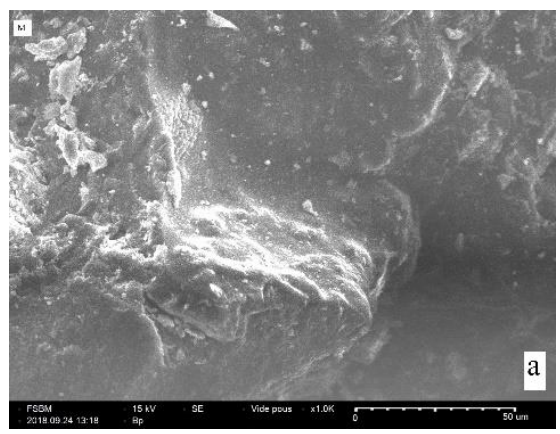

Figure 3. SEM images of raw residual (a) and activated material (b) of Marjoram (M) at $50 \mu \mathrm{m}$

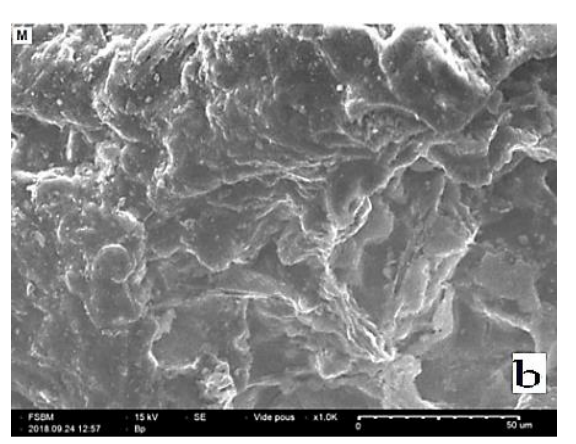

the profile of the studied biomass samples is similar.

\subsubsection{Scanning electron microscopy (SEM) analysis}

The scanning electron microscope is a qualitative observation tool of powder morphology. It provides information on the structure and texture of powder but also on the size and shape of the elementary grains or agglomerates according to the chosen magnification ${ }^{54}$.

The observation of the SEM images of studied adsorbents shows that the external surfaces of materials are relatively heterogeneous with the presence of large cavities, indicating that the porosity of these materials was produced by the attack of the reagent $\left(\mathrm{H}_{3} \mathrm{PO}_{4}\right)$ during activation. In the other side, we have plat structure of raw residual biomass without any porosity (Figures 3-4-5). 

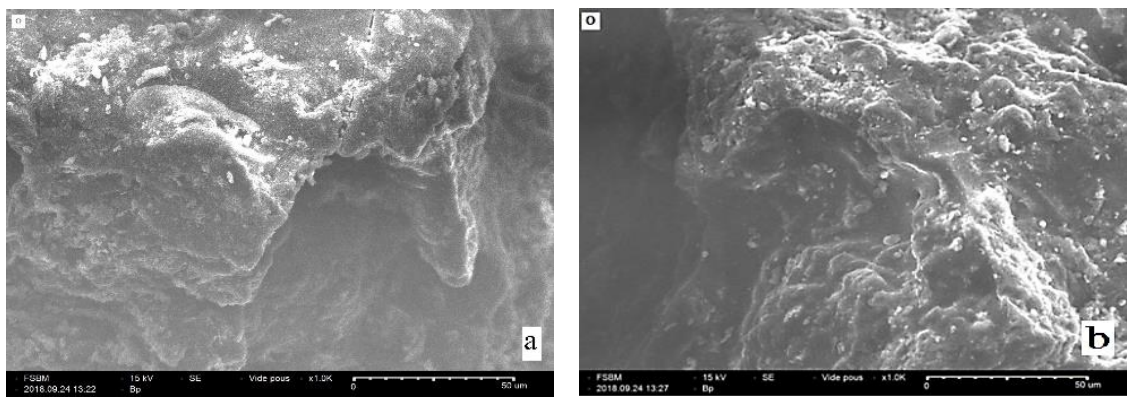

Figure 4. SEM images of raw residual (a) and activated material (b) of Oregano (O) at $50 \mu \mathrm{m}$
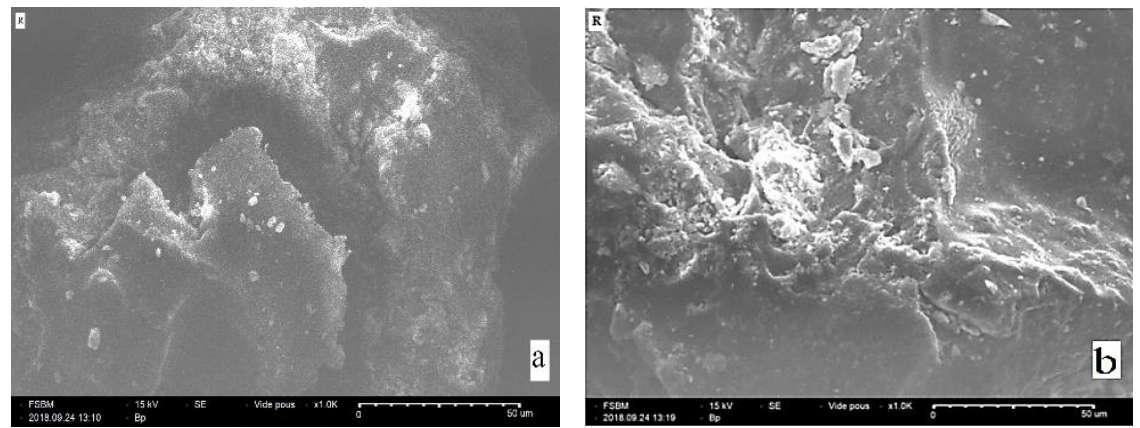

Figure 5. SEM images of raw residual (a) and activated material (b) of Rosmarinus (R) at $50 \mu \mathrm{m}$

\subsubsection{X-Ray Diffraction (XRD) analysis}

The X-Ray Diffraction pattern of the adsorbent materials (Figure 6) exhibit broad peaks and absence of a sharp peak that revealed a predominantly amorphous structure, which is an advantageous
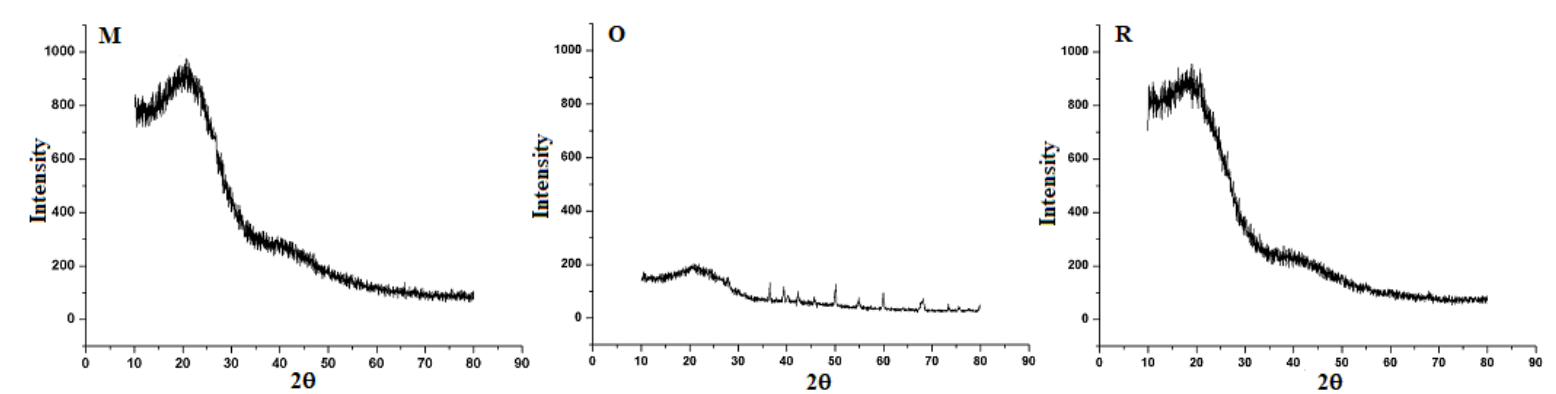

Figure 6. XRD analysis of activated material of Marjoram, Oregano and Rosmarinus

\subsubsection{Raman spectroscopy analysis}

Raman spectroscopy is a measurement tool used to understand the mechanisms and nature of the chemical processes used for the preparation of adsorbent materials from biomass. Since the elaborate materials contain carbon, the spectra often resemble those of amorphous elemental carbon. property for well-defined adsorbents ${ }^{55}$. However, the occurrence of a broad peak around $20^{\circ}$ showed sign of formation of a crystalline carbonaceous structure, resulting in better layer alignment ${ }^{56}$.
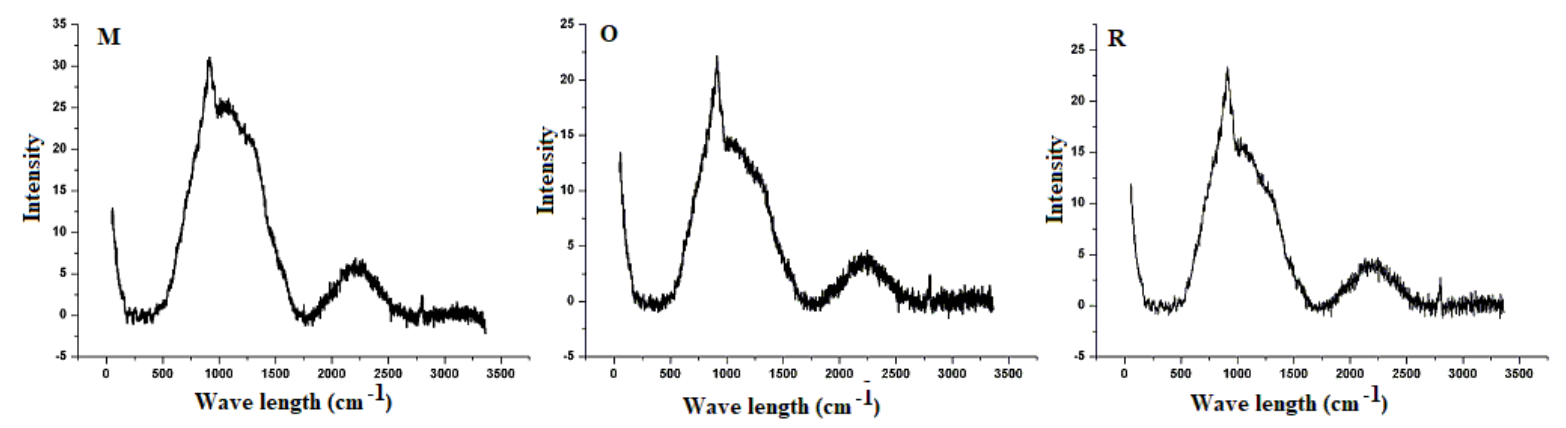

Figure 7. Raman spectroscopy analysis of studied adsorbents 


\subsection{Adsorption proprieties}

\subsubsection{Effect of operating parameters}

\subsubsection{Influence of contact time}

Equilibrium time is one of the crucial parameters for an economic wastewater treatment system ${ }^{58}$. The experimental results relating to the effect of contact time on the removal of methylene blue (MB) are shown in Figure 8. The kinetic curve of methylene blue shows that the equilibrium is fastly established for our adsorbate. This curve presents a rapid increase in the amount adsorbed, which is fixed after $60 \mathrm{~min}$ for methylene blue with amount adsorbed of $68 \mathrm{mg} / \mathrm{g}$ onto the studied adsorbent.

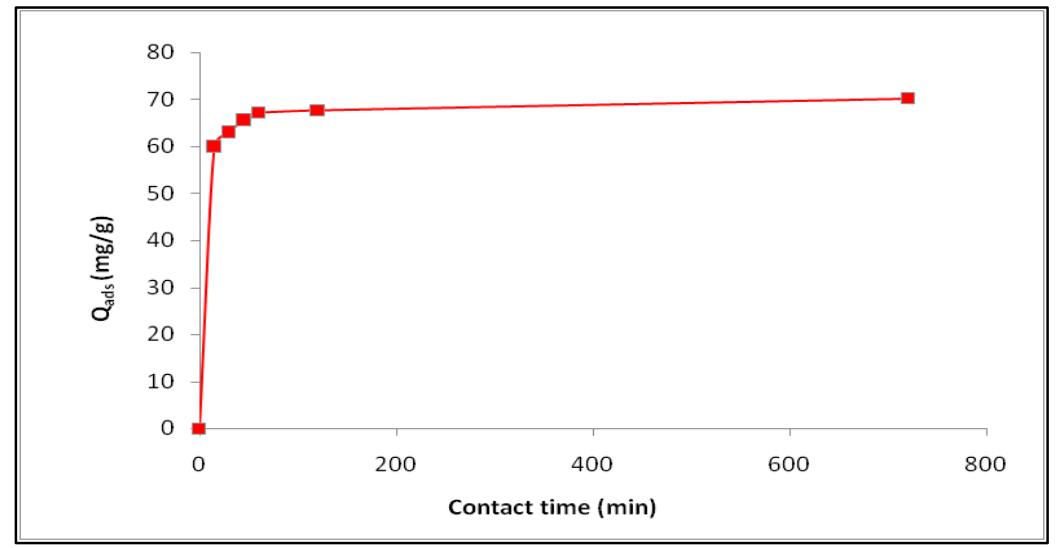

Figure 8. Influence of contact time of $\mathrm{MB}$ adsorption using the studied adsorbent under operating conditions: $\mathrm{T}=298 \mathrm{~K}, \mathrm{pH}$ value $=7$, initial concentration of $\mathrm{MB}=20 \mathrm{mg} / \mathrm{L}$, adsorbent mass $=0.1 \mathrm{~g}$ and stirring speed $=250 \mathrm{rpm}$

\subsubsection{Influence of $\mathbf{p H}$}

The $\mathrm{pH}$ of aqueous solution plays a vital role in the adsorption of dyes onto biomass ${ }^{59}$. The $\mathrm{pH}$ affects significantly the adsorption capacities of the methylene blue onto the biomass. Figure 9 shows the influence of $\mathrm{pH}$ on the adsorption of methylene blue using the best adsorbent for $\mathrm{pH}$ ranging between 3 and 11. The results show that the variation in the residual concentrations of methylene blue is relatively low. The discoloration is; therefore, little influenced by the $\mathrm{pH}$ change. We note that the best performance is obtained when the $\mathrm{pH}$ is neutral.

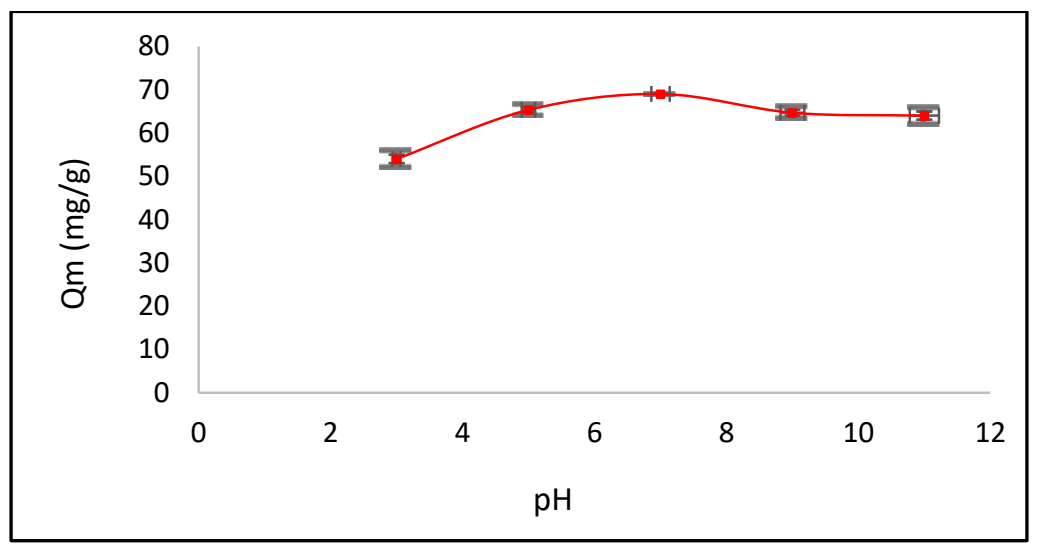

Figure 9. Influence of $\mathrm{pH}$ of $\mathrm{MB}$ adsorption using the studied adsorbent under operating conditions: $\mathrm{T}=298 \mathrm{~K}$, contact time $=60 \mathrm{~min}$, initial concentration of $\mathrm{MB}=20 \mathrm{mg} / \mathrm{L}$, adsorbent mass $=0.1 \mathrm{~g}$ and stirring speed $=250 \mathrm{rpm}$

\subsubsection{Influence of initial concentration}

The effect of the initial dye concentration factor depends on the immediate relation between the dye Concentration and the available binding sites on an adsorbent surface ${ }^{60}$. The effect of the initial methylene blue concentration, on the adsorbed amount, is shown in Figure 10. The amount of methylene blue adsorbed increased with an increase in the concentration of methylene blue. This means when the initial concentration increased from 20 to $120 \mathrm{mg} / \mathrm{L}$. 


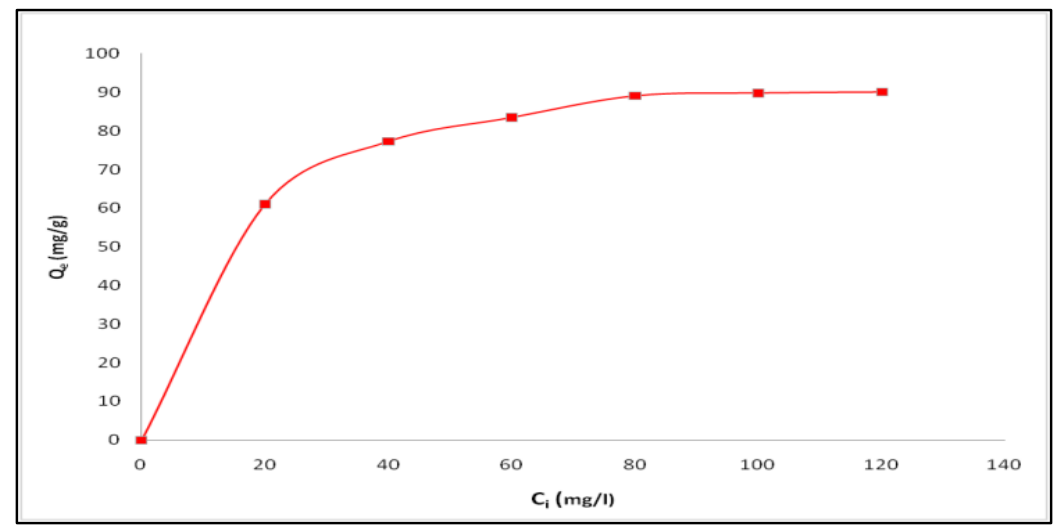

Figure 10. Influence of initial concentration of MB adsorption using the studied adsorbent under operating conditions: $\mathrm{T}=298 \mathrm{~K}, \mathrm{pH}$ value $=7$, contact time $=60 \mathrm{~min}$, adsorbent mass $=0.1 \mathrm{~g}$ and stirring speed $=250 \mathrm{rpm}$

\subsubsection{Adsorption isotherms}

The relationship between the amount of a substance adsorbed per unit mass of adsorbent at constant temperature and its concentration in the equilibrium solution is called the adsorption isotherm. The equilibrium adsorption isotherms are essential in determining the adsorption capacity of methylene blue and diagnose the nature of adsorption onto the adsorbent. The adsorption data were fitted to Langmuir and Freundlich isotherm models described in Section II.5 (Figures 11 and 12). As can be seen

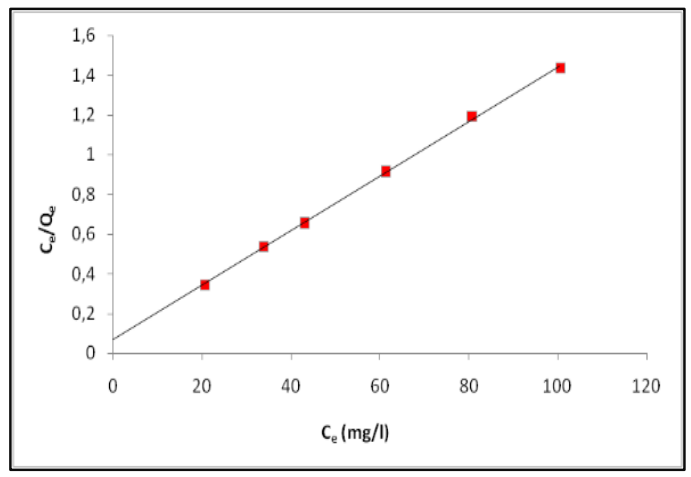

Figure 11. Experimental equilibrium data for modeling with Langmuir isotherm from the regression coefficients in Table 1, the Langmuir model shows the best fit compared to the Freundlich model. The value of $\mathrm{R}_{\mathrm{L}}$ was between 0 and 1 , pointing out the favourable adsorption onto the adsorbent ${ }^{61,62}$. From the best correlation obtained by using Langmuir model ${ }^{61}$, it can be concluded that the monolayer adsorption is more suitable to explain the adsorption of methylene blue and indicates at the same time that chemisorption might also be involved in the sorption process.

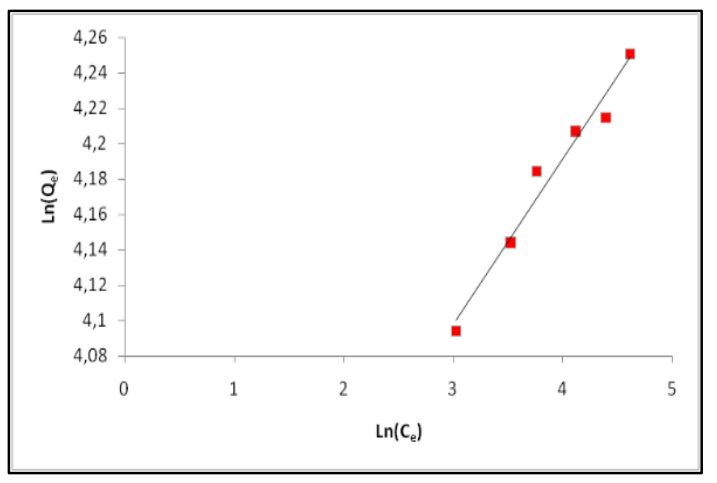

Figure 12. Experimental equilibrium data for modeling with Freundlich isotherm

Table 1. Constants of Langmuir and Freundlich isotherm models for MB adsorbed by the adsorbent.

\begin{tabular}{ll}
\hline Models & \\
\hline Langmuir isotherm & 0.122 \\
Langmuir constant $(\mathrm{b})(\mathrm{L} / \mathrm{mg})$ & 0.120 \\
Equilibrium parameter $\left(\mathrm{R}_{\mathrm{L}}\right)$ & 0.998 \\
Correlation coefficient $\left(\mathrm{R}^{2}\right)$ & \\
Freundlich isotherm & 33.95 \\
Freundlich constant $\left(\mathrm{K}_{\mathrm{F}}\right)(\mathrm{mg} / \mathrm{g} 1 / \mathrm{mg})^{1 / \mathrm{n}}$ & 10.75 \\
Freundlich constant $(\mathrm{n})$ & 0.969 \\
Correlation coefficient $\left(\mathrm{R}^{2}\right)$ & \\
\hline
\end{tabular}

\subsubsection{Adsorption kinetics}

The prediction of kinetics is necessary for the design of adsorption systems. Measurement of adsorption rate constants and order of the reaction are critical physicochemical parameters to evaluate the necessary qualities of a suitable adsorbent. In order to observe the adsorption process of MB onto the adsorbent, pseudo-first-order and pseudo-second-order kinetic models which are described in earlier Section II.6 were implemented. Pseudo-second-order plot (Figure 
13) for the removal of MB by the adsorbent was used to calculate the rate constant $\mathrm{k}_{2}$ and adsorption capacity $\mathrm{q}_{\mathrm{e}}$. In the same manner, the pseudo-firstorder plot (Figure 14) for the removal of MB by the adsorbent was used to calculate the rate constant $\mathrm{k}_{1}$. The adsorption rate constants $\left(\mathrm{k}_{1}\right.$ and $\left.\mathrm{k}_{2}\right)$ and adsorption capacity $\left(\mathrm{q}_{\mathrm{e}}\right)$ for the removal of MB by the adsorbent are reported in Table 2. Since the correlation coefficient is consistent and equal to unity

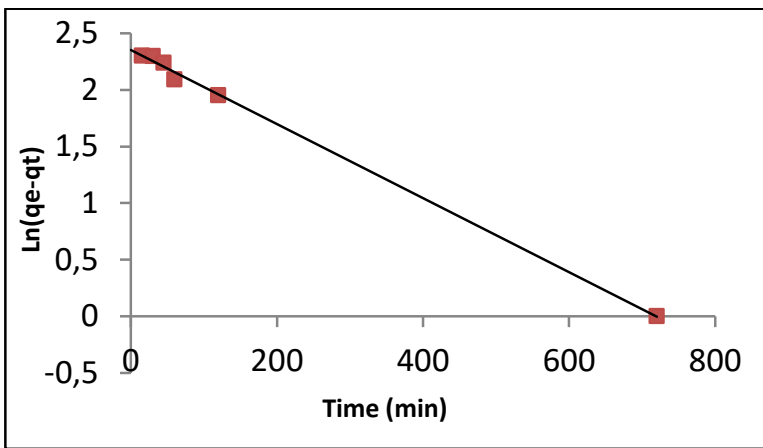

Figure 13. Pseudo-first-order for adsorption of MB for the pseudo-second-order kinetic model than for pseudo-first-order kinetic model (Table 2). The experimental $\mathrm{q}_{\mathrm{e}}$ value was agreed with the calculated $\mathrm{q}_{\mathrm{e}}$ value of pseudo-second-order then the value of pseudo-first-order. This indicating that the adsorption kinetics can be well explained by the pseudo-secondorder kinetic model for the removal of MB by the adsorbent, which is consistent with chemisorptions process $46,48,49,62$.

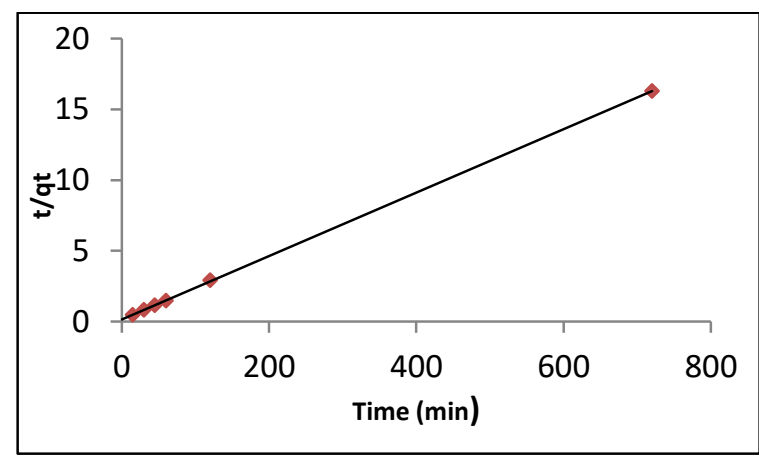

Figure 14. Pseudo-second-order for adsorption of MB

Table 2. Pseudo-first-order and pseudo-second-order kinetic models for removal of MB by the adsorbent.

\begin{tabular}{ll}
\hline Models & MB \\
\hline qe. exp. $(\mathrm{mg} / \mathrm{g})$ & 44.17 \\
Pseudo-first-order & \\
$\mathrm{q}_{\mathrm{e}}$ cal $(\mathrm{mg} / \mathrm{g})$ & 10.51 \\
$\mathrm{~K}_{1}\left(\mathrm{~min}^{-1}\right)$ & 0.006 \\
$\mathrm{R}^{2}$ & 0.998 \\
Pseudo-second-order & \\
$\mathrm{q}_{\mathrm{e}}$ cal $(\mathrm{mg} / \mathrm{g})$ & 45.45 \\
$\mathrm{~K}_{2}\left(\mathrm{~g} \mathrm{mg} \mathrm{min}^{-1} \mathrm{~min}\right)$ & $3.04 .10^{-3}$ \\
$\mathrm{R}^{2}$ & 1 \\
\hline
\end{tabular}

\section{Conclusion}

In this study, three types of adsorbent materials were prepared by an eco-friendly and straightforward process based on residual biomass of Marjoram, Oregano and Rosmarinus by chemical activation with phosphoric acid. The optimization of the transformation process of biomass to adsorbent materials was realized by experimental design. The optimised adsorbent materials obtained were elaborate with $60 \%$ of phosphoric acid in $225^{\circ} \mathrm{C}$ and at $115 \mathrm{~min}$. The characterization of these materials shows the presence of excellent textural and structural properties. Based on preliminary adsorption tests, the adsorbent (M) shows the best adsorption properties compared with the other two samples. The application of the best adsorbent (M) in the removal of methylene blue from aqueous solutions shows that the adsorption process was affected by some experimental parameters such as $\mathrm{pH}$, contact time, and initial concentration. The obtained results showed that the pollutant might be removed with a significant percentage by the adsorbent $(\mathrm{M})$ at a contact time of $60 \mathrm{~min}$ and in a neutral medium of $\mathrm{pH}=7$. Adsorption of methylene blue on the adsorbent was found to follow a pseudo-second-order kinetic model, which is consistent with a chemisorption process. Adsorption isotherms were better described by the Langmuir model in comparison to the Freundlich model, which proves that the adsorption is monolayer. Thus these studies revealed that the studied biomass could be effectively used as an effective adsorbent for the removal of methylene blue from water and wastewater.

\section{Disclosure statement}

No potential conflict of interest was reported by the authors.

\section{References}

1- Q. A. A. Guy, and J. F. Malcolm, Energy from biomass in the UK: Sources processes and biodiversity implications, British Ornithologists 'Union', Ibis, 2006, 148, 180-183.

2- D. C. Hugues, R. Claude, and C. P. Jean, The valorization of Biomass, Information guide for administrations and public institutions, French 
Environment \& Energy Management Agency: Angers, France, 2007, 1-39.

3- I. Ali, New Generation Adsorbents for Water Treatment, Chemical Rev., 2012, 112, 5073-5091.

4- A. A. Basheer, New generation nano-adsorbents for the removal of emerging contaminants in water, J. Mol. Liq., 2018, 261, 583-593.

5- I. Ali, A. A. Basheer, X.Y. Mbianda, A. Burakov, E. Galunin, I. B. Kova, E. Mkrtchyan, A. Tkachev, and V. Grachev, Graphene based adsorbents for remediation of noxious pollutants from wastewater, Environ. Int., 2019, 127,160180.

6- A. T. Hubbard, Encyclopedia of surface and colloid science, Marcel Dekker, New York, 2002, 136-166.

7- I. Ali, and H.Y. Aboul-Enein, Chiral Pollutants: Distribution, Toxicity and Analysis by Chromatography and Capillary Electrophoresis, John Wiley \& Sons: Chichester, UK, 2004.

8- R. A. Ed. Meyers, Encyclopedia of Environmental Pollution and Clean-up, John Wiley \& Sons: New York, 1999.

9- B.Ed. Damia, Emerging Organic Pollutants in Waste Waters and Sludge, Springer: New York, 2005.

10- A. A. Basheer, Chemical chiral pollution: Impact on the society and science and need of the regulations in the 21 st century, Chirality, 2017, 30, 402-406.

11-A. A. Basheer, and I. Ali, Stereoselective uptake and degradation of $( \pm)$-o,p-DDD pesticide stereomers in water-sediment system, Chirality, 2018, 30, 1088-1095.

12-Persistent Organic Pollutants: Impact on Child Health; NLM classification: WA 671, WHO report; World Health Organization: Geneva, 2010.

13-A. Köhler, S. Hellweg, B.I. Escher, and K. Hungerbühler, Organic pollutant removal versus toxicity reduction in industrial wastewater treatment: the example of wastewater from fluorescent whitening agent production, Environ. Sci. Technol., 2006, 40(10), 401-3395.

14-H. J. Ali, A.R. Ramlah, A. Mohd, I. Mohd, and D. W. Lee, Adsorption of methylene blue onto activated carbon developed from biomass waste by $\mathrm{H} 2 \mathrm{SO} 4$ activation: kinetic, equilibrium and thermodynamic studies, J. Desalination and Water Treatment, 2016, 57, 25194-25206.

15-H. Zollinger, Colour Chemistry-Synthesis, Properties of Organic Dyes and Pigments; VCH Publishers: New York, U.S., 1987, 92-100.

16-I. Ali, Al Arsh Basheer, A. Kucherova, N. Memetov, T. Pasko, K. Ovchinnikov, V. Pershin, D. Kuznetsov, E. Galunin, V. Grachev, and A. Tkachev, Advances in carbon nanomaterials as lubricants modifiers, J. Mol. Liq., 2019, 279, 251-266.

17-Y. C. Wong, Y. S. Szeto, W.H. Cheung, and
G. McKay, Adsorption of acid dyes on chitosan equilibrium isotherm analyses, Process Biochemistry, 2004, 39, 693-702.

18-K. Hatice, and K. Ismet, Synthesis, characterization of magnetic chitosan/active charcoal composite and using at the adsorption of methylene blue and reactive blue 4, Microporous and Mesoporous Materials, 2016, 232, 26-38.

19-D. S. Tong, C. H. Zhou, Y. Lu, H. Yu, G.F. Zhang, and W. H. Yu, Adsorption of acid red G dye on octadecyltrimethylammonium montmorillonite, Applied Clay Science, 2010, 50, 427-431.

20-E. A. Burakova, T. P. Dyachkova, A. V. Rukhov, E. N. Tugolukov, E. V. Galunin, A. G. Tkachev, A. A. Basheer, and I. Ali, Novel and economic method of carbon nanotubes synthesis on a nickel magnesium oxide catalyst using microwave radiation, Journal of Molecular Liquids, 2018, 253, 340-346.

21-I. Ali, Z. A. Al-Othman, A. Alwarthan, M. Asim, and T. A. Khan, Removal of arsenic species from water by batch and column operations on bagasse fly ash, Environmental Science and Pollution Research, 2014, 21(5), 3218-3229.

22-I. Ali, and C. K. Jain, Advances in arsenic speciation techniques, International Journal of Environmental Analytical Chemistry, 2004, 84, 947-964.

23-I. Ali, Z. A. AL Othman, and M. M. Sanagi, Green Synthesis of Iron Nano-Impregnated Adsorbent for Fast Removal of Fluoride from Water, Journal of Molecular Liquids, 2015, 211, 457-465.

24-I. Ali, T. A. Khan, and M. Asim, Removal of arsenate from groundwater by electrocoagulation method, Environmental Science and Pollution Research, 2012, 19(5), 1668-1676.

24-I. Ali, Z. A. AL-Othman, and A. Alwarthan, Green synthesis of functionalized iron nanoparticles and molecular liquid phase adsorption of ametryn from water, Journal of Molecular Liquids, 2016, 221, 1168-1174.

25-I. Ali, Z. A. AL-Othman, and A. Alwarthan, Uptake of propranolol on ionic liquid iron nanocomposite adsorbent: Kinetic, thermodynamics and mechanism of adsorption, J. Mol. Liq., 2017, 236, 205-213.

26-I. Ali, and H. Y. Aboul-Enein, Speciation of arsenic and chromium metal ions by reversed phase high performance liquid chromatography, Chemosphere, 2002, 48, 275-278.

27-I. Ali, Z. A. AL-Othman, and O.M.L. Alharbi, Uptake of pantoprazole drug residue from water using novel synthesized composite iron nano adsorbent, J. Mol. Liq., 2016, 218, 465-472.

28-I. Ali, Z. A. AL-Othman, and A. Alwarthan, Sorption, kinetics and thermodynamics studies of atrazine herbicide removal from water using iron nano-composite material, International Journal of 
Environment Science and Technology, 2016, 13, 733-742.

29-I. Ali, O.M.L. Alharbi, Z. A. AL-Othman, A. Y. Badjah, A. Alwarthan, and A. A. Basheer, Artificial neural network modelling of amido black dye sorption on iron composite nano material: Kinetics and thermodynamics studies, J. Mol. Liq., 2018, 250, 1-8.

30-O. Hamdaoui, Batch study of liquid-phase adsorption of methylene blue using cedar sawdust and crushed brick, Journal of Hazardous Materials, 2006, B135, 264-273.

31-O. Hamdaoui, and M. Chiha, Removal of methylene blue from aqueous solutions by wheat bran, Acta Chim. Slov., 2007, 54, 407-418.

32-J. I. Muhammad, and N.A. Muhammad, Adsorption of dyes from aqueous solutions on activated charcoal, Journal of Hazardous Materials, 2007, B139, 57-66.

33-M. C. Ncibi, M. Borhane, and S. Mongi, Investigation of the sorption mechanisms of metal-complexed dye onto Posidoniaoceanica (L.) fibres through kinetic modelling analysis, Bioresource Technology, 2008, 99, 5582-5589.

34-H. R. Nodeh, W.A.W. Ibrahim, I. Ali, and M.M. Sanagi, Development of magnetic graphene oxide adsorbent for the removal and preconcentration of as (III) and as (V) species from environmental water samples, Environ. Sci. Pollut. Res. Int., 2016, 23, 9759-9773.

35-I. Ali, Microwave-assisted economic synthesis of multi-walled carbon nanotubes for arsenic species removal in water: Batch and column operations, J. Mol. Liq., 2018, 271, 677-685.

36-I. Ali, O.M.L. Alharbi, A. Tkachev, E. Galunin, A. Burakov, and V. A. Grachev, Water treatment by new-generation graphene materials: hope for bright future, Environ. Sci. \&Pollut. Res., 2018, 25, 7315-7329.

37-I. Ali, O.M.L. Alharbi, Z. A. ALothman, and A. Alwarthan, Facile and eco-friendly synthesis of functionalized iron nanoparticles for cyanazine removal in water, Colloids and Surfaces B: Biointerfaces, 2018, 171, 606-613.

38-I. Ali, O.M.L. Alharbi, Z. A. ALothman, and A. Y. Badjah, Kinetics, Thermodynamics and Modelling of Amido Black Dye Photodegradation in Water Using $\mathrm{Co} / \mathrm{TiO} 2$ Nanoparticles, Photochemistry and Photobiology, 2018, 94, 935-941.

39-I. Ali, O.M.L. Alharbi, Z. A. ALOthman, A. M. Al-Mohaimeed, and A. Alwarthan, Modeling of fenuron pesticide adsorption on CNTs for mechanistic insight and removal in water, Environmental Research, 2019, 170, 389-397.

40-Z. A. ALOthman, A. Y. Badjah, and Imran Ali, Facile synthesis and characterization of multiwalled carbon nanotubes for fast and effective removal of 4 tertoctylphenol endocrine disruptor in water, J. Mol. Liq., 2019, 275, 41-48.
41-I. Ali, Z. A. ALOthman, and A.Alwarthan, Removal of secbumeton herbicide from the water on composite nanoadsorbent, Desalination and Water Treatment, 2016, 57, 10409-10421.

42-M. C. Ncibi, B. Mahjoub, M. Seffen, F. Brouers, and S. Gaspard, Sorption dynamic investigation of chromium (VI) onto Posidonia oceanic fibres: Kinetic modelling using new generalized fractal equation, Biochemical Engineering Journal, 2009, 46, 141-146.

43-Y. Bulut, and H. karaer, Adsorption of methylene blue from aqueous solution by crosslinked chitosan /bentonite composite, Journal of Dispersion Science and Technology, 2014, 36, 61-67.

44-Z. Aksu, S. C. Seyda, and F. Gonen, Continuous fixed-bed biosorption of reactive dyes by dried Rhizopusarrhizus: Determination of column capacity, Journal of Hazardous Materials, 2007, 143, 71-362.

45-D. O. Kra, N'guadi B. Allou, P. Atheba, P. Drogui, and A.Trokourey, Preparation and Characterization of Activated Carbon Based on Wood (Acacia auriculea formis, Côte d'Ivoire), Journal of Encapsulation and Adsorption Sciences, 2019, 9, 63-82.

46-K. J. L. dos Santos, G. E. de Souza dos Santos, Í. M. Gomes Leite de Sá,

S. H. Vieira de Carvalho, J. I. Soletti, L. Meili, J. L. da Silva Duarte, M. Daltro Bispo, and G. L. Dotto, Syagrusoleracea-activated carbon prepared by vacuum pyrolysis for methylene blue adsorption, Environmental Science and Pollution Research, 2019, 26(16), 16470-16481.

47-O. S. Mamane, M. Siragi Dounounou Boukari, A. R. Chaibou Yacouba, M. Mousbahou Malam Alma, and I. Natatou, Valorization of walnut shells of Balanitesaegyptiaca (L.) Del. and elimination of Chrome in solution, Afrique Science, 2018, 14(3), 167-181.

48-N. Badri, Y. Chhiti, F. Bentiss, and M. Bensitel, Removal of cationic dye by high surface activated carbon prepared from biomass (date pits) by carbonization and activation processes Moroccan, Journal of Chemistry, 2018, 6(4), 767-780.

49-Z. Li, G. Wang, K. Zhai, C. He, Q. Li, and P. Guo, M. Blue Adsorption from Aqueous Solution by Loofah Sponge-Based Porous Carbons, Colloids and Surfaces A: Physicochem. Eng. Aspects, 2018, 28-35.

50-A. Omri, and M. Benzina, Adsorption characteristics of silver ions onto activated carbon prepared from almond shell, Desalination and Water Treatment, 2012, 1-10.

51-G. C. R. Purna, S. Satyaveni, A. Ramesh, K. Seshaiah, K.S.N. Murthy, and N.V. Choudary, Sorption of cadmium and zinc from aqueous solutions by zeolite $4 \mathrm{~A}$, zeolite $13 \mathrm{X}$ and bentonite, Journal of Environmental Management, 2006, 81, 265-272. 
52-G. Mckay, H.S. Blair, and J.R. Gardener, Adsorption of Dyes on Chitin. I. Equilibrium Studies, Journal of Applied Polymer Science, 1982, 27, 3043-3057.

53-C. Raji, and T.S. Anirudhan, Batch Cr(VI) Removal by Polyacrylamide-Grafted Sawdust: Kinetics and Thermodynamics, Water Research, 1998, 32, 3772-3780.

54-S. Claudia, and D.G. Vincenzo, ESEM analysis of chalk microstructure submitted to hydromechanical loading, C. R. Geosciences, 2007, 339, 468-481.

55-A. Omri, M. Benzina, and N. Ammar, Preparation, modification and industrial application of activated carbon from an almond shell, Journal of Industrial Engineering Chemistry, 2013, 19, 2092-2099.

56-L.J. Kennedy, J.J. Vijaya, K. Kayalvizhi, and G. Sekaran, Adsorption of phenol from aqueous solutions using mesoporous carbon prepared by two-stage process, Chemical Engineering Journal, 2007, 132, 279-287.

57-H.I. Aguilar, K.A. Nils, T. López-Luke, F.C.T. Flavio, P.W. Jens, and N. Ornelas-Soto, Surface enhanced Raman spectroscopy of phenolic antioxidants: A systematic evaluation of ferulic acid, p-coumaric acid, caffeic acid and sinapic acid, Vibrational Spectroscopy, 2017, 89, 113-122.
58-K. Kadirvelu, and C. Namasivayam, Activated Carbon from Coconut Corpith as Metal Adsorbent: Adsorption of Cd(II) from Aqueous Solution, Adv. Environ. Res., 2003, 7, 471-478.

59-A.W. Mohamed, J. Salah, and J. Naceur, Effect of temperature and $\mathrm{pH}$ on the biosorption of ammonium onto Posidoniaoceanicafibers: Equilibrium, and kinetic modelingstudies, Bioresource Technology, 2010, 101, 8606-8615.

60-F. Mahammedi, B. Benguella, Adsorption of methylene blue from aqueous solutions using natural clay, Journal Mater. Environ. Sci., 2016, 7, 285-292.

61-I. Langmuir, The constitution and fundamental properties of solids and liquids, Journal of the American Chemical Society, 1916, 38, 2221-2295.

62-F.N. Allouche, and N. Yassaa, Potential adsorption of methylene blue from aqueous solution using green macroalgae Posidoniaoceanica, IOP Conference Series: Materials Science and Engineering, 2018, 323, 1-7. 